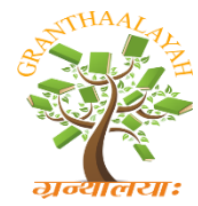

INTERNATIONAL JOURNAL OF RESEARCH GRANTHAALAYAH

A knowledge Repository

Management

\title{
JOB SATISFACTION AND MORALE OF TEACHERS IN TIRUNELVELI DISTRICT
}

\author{
Dr. R. Nagamani Rajan ${ }^{* 1}$, Dr. K. Subramanian ${ }^{2}$ \\ ${ }^{* 1}$ M.Com., M.Phil., MBA., Ph.D., Assistant Professor in Commerce, Manonmaniam Sundaranar \\ University College, Panagudi, Tirunelveli, India \\ ${ }^{2}$ M.Com., M.Phil., MBA., Ph.D., Associate Professor in Commerce (Retd.,), Controller of \\ Examination, Sadakathullah Appa College, Tirunelveli, India
}

DOI: https://doi.org/10.29121/granthaalayah.v5.i4(SE).2017.1943

\begin{abstract}
Education is the prime key to the growth and development of a society in all its spheres. Education is a social sector of an economy. It is the infrastructure for the economic development. Education is provided in different forms at different levels in Tirunelveli District. All sections of people including women, Children and weaker sections tend to take care of their health and lead a healthier life in the most literate nations. In this connection, the researcher studies about job satisfaction and morale of teachers in Tirunelveli district. This study concludes that several factors play dominant role in the enhancement of job satisfaction of teachers. The major factor is connected with finance.
\end{abstract}

Keywords: Education; Economy; Teachers; Job Satisfaction \& Finance.

Cite This Article: Dr. R. Nagamani Rajan, and Dr. K. Subramanian. (2017). "JOB SATISFACTION AND MORALE OF TEACHERS IN TIRUNELVELI DISTRICT." International Journal of Research - Granthaalayah, 5(4)SE, 7-13. https://doi.org/10.29121/granthaalayah.v5.i4(SE).2017.1943.

\section{Introduction}

Teachers constitute a significant component of the work force of the Tirunelveli District. Working in a service sector these teachers play a peculiar role in moldings the future generation of this District. The nature of the job is also peculiar in the same that they produce not goods and services but literates, skilled work force, Professional scientists and experts. They promote research in various fields and discriminate the fruits of research among the learning community. 


\section{Scope and Objective of the Study}

The study is related to Job Satisfaction and morale of teacher in general and special reference to different aspects of teachers based on the sex, age, general educational qualification, Professional Educational Qualification, Designation, Experience and Family size, with this board scope, the study has the following specific objectives:

1) To identify and evaluate the various factors contributing to the job satisfaction and morale of teachers in Tirunelveli District.

2) To evaluate Socio-Economic and Environmental sectors that influence the Job Satisfaction and morale of Teaching community.

3) To evaluate the impact of the different segments of educational sector on job satisfaction and morale of the teaching community.

4) To give suggestions to enhance the level of Job Satisfaction and the morale of the teachers.

As with any worker, Job satisfaction among the teachers is a key factor influencing not only their morale and Professional success but also the quality of education imported to the student community. Therefore, it is contribute towards teacher's job satisfaction and morale.

\section{Determination of Job Satisfaction}

Job Satisfaction is considered to be one of the most controversial issues of today not only in Tirunelveli, but also all the world over. In modern times, it is generally felt that mechanization promotes job satisfaction. Job Satisfaction is affected by the frustration of the employees the disappointment or by the achievements and the happiness derived at the work place. As human beings and as members of an organization, their thoughts and feelings strongly influence their behavior on the job. One of the surest signs of the deteriorating conditions in an organization is the low job satisfaction of its employees. It is one of the important causes for strikes, absenteeism, employees' low turnover, low performance disciplinary problems and the like.

\section{The following are the factors that affect the levels of job satisfaction of the Teachers.}

1) Personality

2) Financial incentives

3) Expectations

4) Job Aspirations

5) Training and Promotional opportunities

6) Job Tenure and Job characteristics

7) Culture

8) Professional needs

9) Environmental and Genetic components

10) Standards of comparison 


\section{Measurement of the Level of Job Satisfaction of Teachers}

Table 1:

\begin{tabular}{|l|l|}
\hline JOB SATISFACTION LEVEL & SCORE RANGE \\
\hline-3 to 0 & Dissatisfied \\
\hline $1-10$ & Low level \\
\hline $11-20$ & Medium level \\
\hline 21 and above & High level \\
\hline
\end{tabular}

\section{Hypotheses}

The following are the hypotheses formulated.

Teachers working in aided colleges and self-financing colleges do not differ significantly with regard to the level of Job Satisfaction on the factor 'Physical facilities'.

\section{Physical Facilities and Job Satisfaction}

This factor is concerned with the Physical facilities conducive to teaching like laboratory, Library and Faculty room which make the place of work more comfortable.

To measure the level of Job Satisfaction on the factor 'Physical facilities', the Mean, Standard Deviation (SD), Co-efficient of variation $(\mathrm{CV})$ and the '+' value are calculated and presented in Table.

Table 2:

\begin{tabular}{|l|l|l|}
\hline PARTICULARS & AIDED COLLEGES & SELF FINANCING COLLEGES \\
\hline Mean & 18.86 & 20.03 \\
SD & 3.12 & 2.88 \\
CV & 16.53 & 14.37 \\
\hline '+' value & $\mathbf{2 0 . 4 5}$ & $\mathbf{1 7 . 8 2}$ \\
& (at 0.05 level) & (at 0.05 level) \\
\hline
\end{tabular}

It is found that the mean score of 18.86 for aided college teachers is above the neutral point further the ' + ' value shows that it is significant at 0.05 level. Hence the teachers of aided colleges are satisfied with the factor 'Physical Facilities'. The mean score of 20.03 for selffinancing college teachers is also above neutral point. Further, the ' + ' value shows that it is significant at 0.05 level. Hence, the teachers of self-financing colleges are also satisfied with the factor physical facilities.

It is inferred that mean job satisfaction score of teachers working in aided colleges is 18.86 . The mean score (20.03) of those working in self-financing colleges is higher than that of aided college teachers.

The reasons are: Self-financing colleges have more physical facilities. They need not depend on University Grants Commission for these facilities. Since they are charging higher fees, they are able to provide more physical facilities. 
The null hypothesis framed is "Teachers working in aided colleges and Self-financing colleges do not differ significantly with regard to the level of satisfaction on the factor 'Physical facilities"”.

The level of attitude of teachers towards teaching does not differ significantly with regard to the job satisfaction factor 'academic policies'.

This factor deals with aspects related to teachers scope for framing academic policies, academic freedom the teachers have their role in designing curriculum, academic decision-making and the like which do have intrinsic effect on the job satisfaction of teachers.

To measure the level of satisfaction on the factor 'academic policies' the mean, standard deviation (SD), Co-efficient of variation $(\mathrm{CV})$ and the ' + ' value are calculated

Table 3: Job factor 'Academic Policies' and the '+' value

\begin{tabular}{|l|l|l|}
\hline PARTICULARS & AIDED COLLEGES & SELF FINANCING COLLEGES \\
\hline Mean & 12.21 & 11.84 \\
SD & 1.88 & 1.64 \\
CV & 15.43 & 13.84 \\
\hline '+' value & $\mathbf{2 4 . 4 8}$ & $\mathbf{1 9 . 7 0}$ \\
& (at 0.05 level) & (at 0.05 level) \\
\hline
\end{tabular}

It shows that the teacher of aided colleges and self-financing colleges are dissatisfied with the factor 'academic policies'. It is found that there are frequent changes in the academic policies of the University. This is the reason for the dissatisfaction of college teachers with the factor 'academic policies'.

The null hypothesis framed is Teachers working in aided colleges and self-financing colleges do not differ significantly with regard to the level of job satisfaction on the factor "Academic policies'.

\section{Teachers' Morale}

The Teacher has to play a multiple and diversified role in keeping up with the expectations, the ambitions and the needs of his several associate groups, such as the management, the principal or Headmaster, his colleagues his pupils and the community at large lack of adequate recognition, unjustified criticisms, unsatisfactory and disgusting mode of treatment, expectation of results without proper reward, indiscipline aided and abetted by pupils, his colleagues, by the head of the institution or even by outside elements, exposure of innocuous short comings in the presence of others, failure to recognize the basic environmental and individual needs, frequent absenteeism from work and the like are the main factors that signify "Teachers Morale". Morale is an intriguing variable and it is well known that the pupils will respond according to their general emotional state of readiness. Morale is both an individual as well as a group phenomenon. 
In the opinion of Kahn and Katz, "Morale is a combination of attitudes towards the company Job and the immediate supervisor" 1

In the words of Robert M. Guion, "The extent to which an individual's needs are satisfied and the extent to which the individual perceives the satisfactions as stemming from his total job is morale" 2

The morale of the employees can be measured, in general, with reference to the following factors.

1) Gender

2) Educational qualifications

3) Designation of a Teacher

4) Teaching Experience

5) Nature of the School-Management

6) Locality

7) Age

8) Size of the family of the Teacher

9) Job Discrimination index

10) Job involvement

11) Family satisfaction

12) Life satisfaction

\section{Materials and Methods}

- This study is based on both Primary data and Secondary data.

- The Primary data were collected the help of interview schedules.

- The secondary data have been collected from various published and unpublished records of Government and Non-government institutions.

\section{Determination of Morale of Teachers}

1) Opinion of Teachers about their liking towards the teaching profession.

2) Level of liking of the Teachers towards academic work related to their profession.

3) Level of liking of the Teachers towards non-academic work related to their profession.

\section{Tools of Analysis}

1) The data were analyzed by using relevant statistical techniques like mean, Standard deviation, Co-efficient of variation and ' + ' test.I

2) To assess the satisfaction level of teachers has been computed using the following formula. 
Satisfaction index:

$$
=\frac{\text { Number of 'Satisfactory' responses }}{\text { Total number of Teachers }}
$$

3) For the purposes comparison of the actual level of dissatisfaction is computed as an index using the formula.

Index of dissatisfaction:

$$
=\frac{\text { Actual Score }}{\text { Maximum Score }}
$$

\section{Result and Discussion}

Level of liking of Teachers towards their academic work and Non-academic work. Using teachers responses the index value in respect of each dimension of the both academic and nonacademic work have been computed and presented in Table.

Table 4:

\begin{tabular}{|l|l|l|l|l|}
\hline Dimensions of work & Positive scores & Negative Scores & Total Scores & Index Value \\
\hline Academic work & +854 & -202 & +652 & 0.61 \\
Non-academic work & +597 & -147 & +450 & 0.61 \\
\hline Total & $\mathbf{+ 1 4 5 1}$ & $\mathbf{- 3 4 9}$ & $\mathbf{+ 1 1 0 2}$ & - \\
\hline
\end{tabular}

\section{Summary of Findings}

1) It is interesting to note that both the self-financing and aided college teachers are satisfied with the factor 'Physical facilities'. Since the aided colleges are managed privately, they are able to provide adequate physical facilities, Comparatively; Self-financing college teachers feel that they are satisfied and slightly better than those of the aided college teachers. Since, they charge higher fees, they are able to provide more physical facilities.

2) The teachers must be given academic freedom. They must have a role in designing curriculum and academic decision-making. Since, academic policies of the Universities undergo frequent changes, the teachers of aided colleges and self-financing colleges are dissatisfied with the factor 'academic policies'

3) 'Salary and fringe benefits' are considered an important factor for job satisfaction. Selffinancing college teachers are dissatisfied with the factor 'Salary and fringe benefits'. They are not paid University Grants Commission Scales of pay. In most of the colleges, they are paid only a consolidated pay. They are not provided with medical leave and earned leave facilities as provided in the aided colleges. It is also found that the teachers working in self-financing colleges are less satisfied with this factor than the aided college teachers. The reasons are obvious.

4) The teachers of the aided colleges are satisfied with the factor 'Job security'. But the teachers of the Self-financing colleges are dissatisfied with the factor 'Job Security'. They have the fear of losing the job at any time. They do not have a job security. 


\section{Suggestions for Future Research}

This study is limited to teachers working in Tirunelveli District. More intensive studies covering all the teachers working in the Universities. Professional colleges and other colleges will throw more light on different issues related to job satisfaction.

\section{Conclusion}

This study concludes that several factors play dominant role in the enhancement of job satisfaction of teachers. The major factor is connected with finance. Having admitted the fact that the teachers form the backbone of education, their job satisfaction must be maintained at the highest possible level at all costs. To remedy all evils, the Government must enact very stringent legislation to enforce quality in these institutions even if it involves some financial assistance from the Government. This situation should be an eye-opener for the Government. If the aforesaid suggestions are carried out by the Government as well as the management of the Institutions, the job satisfaction of the teachers will improve and there by India will become a knowledge super power in the years to come.

\section{References}

[1] Golden, S. A. R. (2011). An Analysis Of Mental Stress In Heavy Alloy Penetrator Project, Tiruchirappalli. SELP Journal of Social Science, 13.

[2] Golden, S. A. R. (2017). Attitude of Students and Teachers towards E- Learning - An Analysis. Recent Research in Social Science \& Humanities, 1, 5-10.

[3] Golden, S. A. R. (2016). RURAL STUDENTS' ATTITUDE TOWARDS ENGLISH AS MEDIUM OF INSTRUCTION IN HIGHER EDUCATION - AN ANALYSIS. International Journal of Research, 3(Special Issue - 16), 1-10.

[4] Golden, S. A. R. (2017). Recent Research In Social Science \& Humanities.

[5] Pestonjee D.M. Motivation and Job satisfaction Macmillan India Ltd., New Delhi, 1991.

[6] R.L. Khan and D Katz, leadership practice in Relation to productivity and morale, print well publications, Jaipur, 1995

[7] Ramakrishnaiah, Job Satisfaction of College Teachers Discovery Publishing House, New Delhi, 1998.

[8] Regi, S. B., \& Golden, S. A. R. (2014). A DESCRIPTIVE STUDY ON THE ROLE OF CONSUMER PSYCHOLOGY AND BEHAVIOUR IN PRODUCT PURCHASING”. Indian Streams Research Journal, 3(12), 1-6.

[9] Robert M. Guion, 'Some definitions of morale' Personal Physiology, King books publishers Manu Rastogi New Delhi 1958 pp 59-60.

[10] Vinodhkumar, D., \& Pankajam, R. SOCIAL INTELLIGENCE AND ACHIEVEMENT IN SCIENCE AMONG HIGHER SECONDARY SCHOOL STUDENTS.

[11] Shankar, C. AWARENESS OF E-LEARNING AMONG PROSPECTIVE TEACHER EDUCATORS (M. Ed. SCHOLARS). 